\title{
Review: Factors affecting fouling in conventional pens for slaughter pigs
}

\author{
M. L. V. Larsen ${ }^{\dagger}$, M. Bertelsen and L. J. Pedersen \\ Department of Animal Science, Aarhus University, Blichers Allé 20, DK-8830 Tjele, Denmark
}

(Received 3 January 2017; Accepted 26 May 2017; First published online 11 July 2017)

\begin{abstract}
This review assesses factors affecting fouling in conventional pens for slaughter pigs. Fouling of the pen happens when pigs change their excretory behaviour from occurring in the designated dunging area to the lying area. This can result in a lower hygiene, bad air quality, extra work for the farmer, disturbance of the pigs' resting behaviour and an increase in agonistic interactions. A systematic search was conducted and results narrowed down to 21 articles. Four factors were found to affect fouling directly: insufficient space allowance, the flooring design of the pen, the thermal climate and pigs' earlier experience. Further, these primary factors are affected by secondary factors such as the shape of the pen, the weight of the pigs and especially the heat balance of the pigs, which is affected by several tertiary factors including, for example, temperature, humidity and draught. Results indicate that the most important factor to control when trying to prevent fouling of a pen is the pen climate. An appropriate climate may be accomplished through floor cooling in the designated lying area, sprinklers above the designated dunging area and by ensuring a more optimal ambient temperature curve that also fits the weight of the pigs in different stages of the production. All in all, fouling of the pen in conventional slaughter pigs is a multifactorial problem, but it is important to focus on increasing the comfortability, and especially the climate, of the designated lying area.
\end{abstract}

Keywords: fouling, thermoregulatory behaviour, lying behaviour, excretory behaviour, slaughter pigs

\section{Implications}

Fouling is a multifactorial problem affected by both the thermal climate, the space allowance, the flooring design and the pigs' earlier experience. The most important factor to consider to prevent fouling is the climate of the pen, and especially ensuring the highest comfortability in the designated lying area. This can be accomplish through, for example, floor cooling of the lying area, sprinklers above the dunging area or by ensuring a more optimal ambient temperature curve that better fits the weight of the pigs in different stages of the production.

\section{Introduction}

Fouling of the pen happens when pigs change their excretory behaviour from occurring in the designated dunging area to the lying area. This can result in a lower hygiene, bad air quality, extra work for the farmer, disturbance of the pigs' resting behaviour and an increase in agonistic interactions (Aarnink et al., 1996; Hillmann et al., 2004; Smulders et al., 2006). Thus, there is a need for prevention of fouling.

\footnotetext{
† E-mail: mona@anis.au.dk
}

However, fouling is a multifactorial problem and thus, prevention is not a straightforward task. Conventional slaughter pigs are often housed in indoor pens with fully or partly slatted floors. The partly slatted floor pens offer a solid lying area that is more comfortable to rest on and aims at encouraging pigs to differentiate between the solid and slatted floor when resting. However, some pen designs work better than others to ensure this differentiation. Also, Randall et al. (1983) mention that pigs usually eat, drink and then excrete in that order which is why the feeder is often placed close to the lying area and the drinker close to the dunging area. Actually, pigs are known as clean animals in the sense that they keep their lying and dunging areas separate (Aarnink et al., 2006). In a study by Stolba and Wood-Gush (1989), pigs kept in a semi-natural environment rarely defecated closer than $5 \mathrm{~m}$ from their nest site. This is supported by the findings of Salomon et al. (2007) for organic pigs housed outdoors, who also saw that the area close to the nest was kept free of dung, and the findings by Olsen et al. (2001) where most of the excretory behaviour were performed in the outside runs. This suggests that pigs may change their lying behaviour and thereafter their excretory behaviour to the area previously used for resting, or that pigs 
change their lying behaviour after a change in excretory behaviour. Pigs only have very few sweat glands, mainly on the snout, and thus they must change their behaviour in order to cool themselves (Sumena et al., 2010; Olczak et al., 2015). This includes changing from sternal to lateral lying posture to maximise heat loss, avoiding contact with pen mates, wallowing and lying in cooler and/or more draughty areas (Olsen et al., 2001; Ekkel et al., 2003; Spoolder et al., 2012). If the pigs, on the other hand, are cold, they will huddle more, lay in a sternal posture to minimise heat loss and seek away from draughty and cold areas (Hillmann et al., 2004; Huynh et al., 2005a; Aarnink et al., 2006). Further, pigs lie down for at great part of the day (Ekkel et al., 2003), but there is a tendency for more pigs to lie down when temperatures increase (Huynh et al., 2005a; Spoolder et al., 2012). The same is seen when humidity increases (Huynh et al., 2005a). More pigs lying in the pen means that more of the total floor space will be occupied as a lying pig takes up more space than a standing or sitting one. Also, a pig exposed to heat stress will seek to lie without contact with pen mates but with as much contact to the floor as possible. This, once again, takes up even more floor space (Hillmann et al., 2004 and 2005). When a smaller part of the floor is available for moving around at high temperatures, a pig may be restricted in getting to and using the dunging area, and instead being forced to use the area it is currently in for defecation; or the pig may be forced away from its designated lying area to perform thermoregulatory behaviour. Pigs need both static space (occupied by the body of the pig), activity space (feeding and excretion separated) and social space (for social behaviour) (Spoolder et al., 2012). If the space requirement is not met, pigs might not be able to make their way to a designated dunging area or to differentiate between spaces. However, excessive space allowance may result in pigs not being motivated to move away from the other pigs to perform their excretory behaviour. Thus, based on the above, an inappropriate climate or space allowance may result in fouling of the pen.

This review aims to summarise, based on the existing literature, which factors affect fouling in conventional slaughter pigs. Further, this review aims to summarise which actions that can help prevent fouling and to identify future perspectives for research within this area.

\section{Methods}

A literature search was performed on 26 February 2016 in the database Web of Science. The search strategy included three criteria: (1) the study should be of living weaner or slaughter pigs (from $7 \mathrm{~kg}$ to slaughter at around $110 \mathrm{~kg}$ ), (2) the pigs included in the study should be housed under conventional production standards, (3) the study should focus on investigating lying or dunging behaviour of pigs, fouling or closely related terms. The search only included English-language articles but with no limitation on time span (all years included). The following search strategy was used on the subject fouling: Pen Fouling or 'Dunging Pattern' or
'Dunging preferences' or 'Excretory behavio*' or 'excreting behavio ${ }^{* \prime}$ or 'eliminative behavio *' or 'eliminatory behavio*" or 'Pen Hygiene' or 'Lying behavio*' or 'Thermoregulatory behavio*', whereas the following search strategy was used on the object pig: Pig* or Swine or Porcine* or GrowingFinishing or 'Slaughter Pig *' or 'Fattening pig ${ }^{* \prime}$ or 'Finishing pig' or Piggery NOT piglet* NOT sow* NOT cow* NOT goat*. The two search strategies were combined in the end.

\section{Results and discussion}

The literature search yielded 127 potential articles. Title and abstracts of the 127 articles were screened to identify those relevant, and articles were selected if they met the above mentioned criteria. This resulted in 28 articles for which full articles were retrieved for further assessment. After reading the full texts, further seven articles and proceedings were removed as they presented the same data as other studies. The end result was 21 articles of relevance.

The results obtained from the current literature study is summarised in Figure 1. Figure 1 illustrates that four main factors affect fouling directly: space allowance, the flooring design of the pen, the thermal climate and pigs' earlier experience. Other factors can be considered secondary, affecting one or more of the primary factors, or even tertiary only affecting the secondary factors directly. Figure 1 also illustrates described preventive actions against fouling and how these affect the risk factors of fouling. The discussion is build around Figure 1 with headings complying with the primary factors and followed by a description of the preventive actions.

\section{Space allowance}

The effect of insufficient space allowance on fouling of the pen is straightforward. If the pigs are housed at a too low space allowance they cannot move as easily between the different parts of the pen and might be forced to perform their excretory behaviour in the area where they are currently placed. The negative relationship between space allowance and fouling was indirectly confirmed by Hillmann et al. (2005). They saw a tendency for pigs spending more time lying in the dunging area in pens with a smaller space allowance per pig $\left(0.7 \mathrm{~m}^{2} / \mathrm{pig}\right.$ compared with $\left.1.4 \mathrm{~m}^{2} / \mathrm{pig}\right)$ and they started doing so at lower temperatures. However, at temperatures above $25^{\circ} \mathrm{C}$, pigs in the pens with larger space allowances would also start to lie in the dunging area. Another study found that a larger group size at similar space allowances (33 to 42 rather than 17 to 21 pigs/pen) resulted in pigs becoming more wet and dirty (Jensen, 2003, cited by Jensen et al., 2012). Hacker et al. (1994) found that lower space allowances (comparing 0.64 to $1.0 \mathrm{~m}^{2} / \mathrm{pig}$ ) increased the effect of other factors such as open partitionings or inappropriate placement of the nipple drinker making the pen dirtier at high $v$. low space allowances. However, a small increase in available space was not found to reduce fouling in slaughter pigs in a study by Jensen et al. (2012) comparing 0.67 to $0.79 \mathrm{~m}^{2} / \mathrm{pig}$, though the authors acknowledge that 


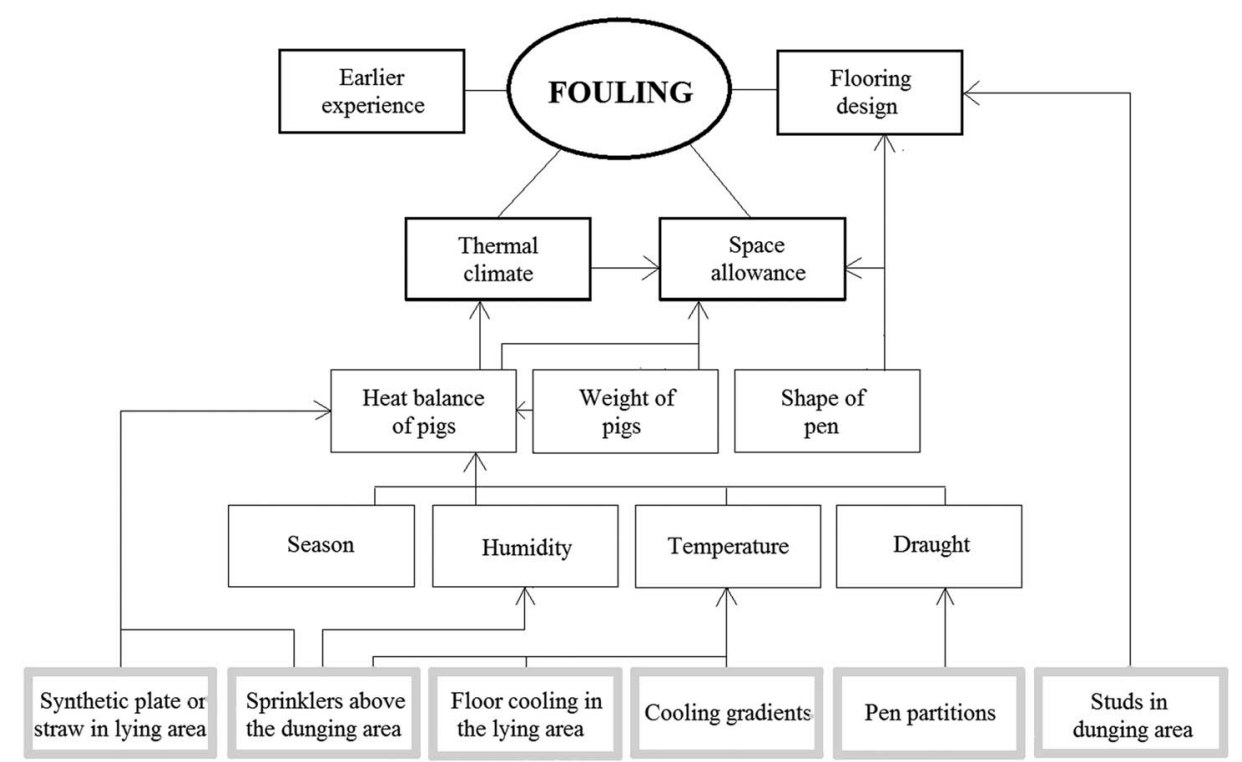

Figure 1 Flowchart presenting factors affecting fouling, directly (bold lined boxes) and indirectly, and currently known actions against fouling (grey lined boxes).

greater differences may have caused an effect on fouling. Hillmann et al. (2005) found a connection between the effect of space allowance and temperature which was confirmed by Spoolder et al. (2012). They found a significant relationship between the space requirements of a pig, its BW and increasing ambient temperatures with pigs taking up more space with increasing weight and temperatures. This relationship is probably due to the change in lying behaviour of pigs at higher temperatures and the fact that a heavier pig has a higher heat production. Spoolder et al. (2012) suggested that if the minimum legal space allowance is applied, then animals above $85 \mathrm{~kg}$ are all housed at too high stocking densities. Ekkel et al. (2003) also found, based on lying patterns of pigs from different weight classes, that a pig of $100 \mathrm{~kg}$ should have $0.76 \mathrm{~m}^{2}$ to lie on, which is more than the minimum requirement of $0.65 \mathrm{~m}^{2}$ for a pig of 85 to $110 \mathrm{~kg}$ (EU council Directive 2001/88/EC). Randall et al. (1983) found that a space allowance of neither less nor more than $120 \mathrm{~kg} / \mathrm{m}^{2}$ resulted in the cleanest lying areas. However, the space allowance also depends on the shape of the pen and a narrow pen can result in pigs not being able to move between the designated lying and dunging areas (Randall et al., 1983). An excessive space allowance in the resting area is not preferable either because too much space may prevent the pigs from being motivated to move outside the resting area to perform their excretory behaviour. With too abundant space in the resting area it has been observed that pigs often defecate in unoccupied corners or against walls (Aarnink et al., 1993).

The above studies indicate that space allowance may have a preventive effect on fouling if the space allowance is sufficient without being excessive. Also, the above studies indicate that the effect of and thereby choice of space allowance depends on the shape of the pen, the weight of the pigs and the environmental temperature. Future research should focus on the direct effect of space allowance on the incidence of fouling in conventional slaughter pigs at space allowances above the one chosen by Jensen et al. (2012). Further, it could be interesting to investigate whether a design without corners in the designated lying area could prevent pigs from performing their excretory behaviour in these areas.

\section{Flooring design}

The importance of a sufficiently large slatted floor area to keep the pen clean was confirmed by Rantzer and Svendsen (2001). They found that weaners in pens with around $36 \%$ slatted floor had a better hygiene than weaners in pens with solid floors and only $20 \mathrm{~cm}$ urine drainage. However, pigs prefer to lie on the solid floor when not in heat stress (Aarnink et al., 1996) and thus to improve animal welfare the floor should not only consist of slatted floor. The pen design should, however, allow pigs to be able to distinguish the lying area from the dunging area. This appear to be easier if the dunging area and thereby the slatted floor is placed at the bottom compared with at the long side of a narrow pen (Randall et al., 1983). Also, there is an interest in reducing the slatted area to reduce ammonia emission. A decrease in the proportion of slatted floor from $50 \%$ to $25 \%$ was found to increase the amount of fouling and thereby ammonia emission (Aarnink et al., 1996). However, in the $50 \%$ slatted pens, the slatted area was divided between the two ends of the pen with $25 \%$ in each end. If the slatted floor had been only in the backend of the pen (where most of the defaecations and urinations occurred independent of proportion of slats) the results might have been different. Contradictory to these results, Huynh et al. (2004) found that pens with 15\% slatted floor in the front and $40 \%$ slatted floor in the back were cleaner than pens with only $40 \%$ slatted floor in the back. The authors suggest themselves that this could partly be explained by the convex shape of the $40 \%$ floors in the first mentioned pens. When considering the increased 
attention on ammonia emission, it is surprising that we did not locate published studies comparing different proportions of slatted floors on the incidence of fouling without confounding effects of the placement of the slats. This is definitely a gap in our knowledge towards both preventing fouling and reducing the ammonia emission. Aarnink et al. (1997a) investigated the effect of different types of slatted floor on fouling and ammonia emission comparing concrete, metal and cast iron slats. Metal slats led to the lowest level of ammonia emission, but did not differ from concrete slats when considering fouling. However, cast iron slats resulted in the dirtiest pens and it was suggested that the pigs walked less steadily on these slats which could discourage them from using the dunging area. All in all, not many studies have looked into the effect of either type of slats or proportion of slatted area in the pen. The above studies suggest that both factors could be important for the prevention of fouling, but more research is needed to implement this knowledge in practice. For example, some pens also include drained flooring consisting of slats with a higher width than normal slatted flooring. No studies with drained flooring could be located even though this could be a compromise to decrease ammonia emission from the slatted floor and fouling on the solid floor.

\section{Thermal climate}

If pigs choose to lie in the designated dunging area, they no longer perform their excretory behaviour there and will choose to do so in the designated lying area instead, resulting in fouling of the pen. As discussed above, pigs may be forced to lie in the dunging area due to insufficient space allowance. However, the lying behaviour of pigs is also affected by the climate of the pen including temperature, humidity and draught, as already described in the introduction.

Multiple studies have shown that the degree of fouling increases at high ambient temperatures (Huynh et al., 2005a; Aarnink et al., 2006; Savary et al., 2009; Spoolder et al., 2012). This is thought to be caused by the pigs' desire to cool themselves by lying on the slatted floors measured to be $3^{\circ} \mathrm{C}$ to $5^{\circ} \mathrm{C}$ cooler than the solid floor (Randall et al., 1983). Further, pigs react faster to an increase in temperature at higher humidities (Huynh et al., 2005a), and Aarnink et al. (1997b) found that more pigs lay in the dunging area during summer than during winter. Draughty or cold lying areas will also discourage the pigs from choosing this site for resting (Randall et al., 1983). However, this knowledge is only interesting in practice if the optimal and inflection temperatures are known. Hillmann et al. (2004) found that pigs weighing $>85 \mathrm{~kg}$ were comfortable at a temperature range of $5^{\circ} \mathrm{C}$ to $17^{\circ} \mathrm{C}$. Pigs weighing 50 to $70 \mathrm{~kg}$ were comfortable at $10^{\circ} \mathrm{C}$ to $17^{\circ} \mathrm{C}$ and smaller pigs of 25 to $35 \mathrm{~kg}$ at $19^{\circ} \mathrm{C}$ to $21^{\circ} \mathrm{C}$. Lower and upper optimal temperature thresholds were indicated by $20 \%$ of the pigs huddling and by $20 \%$ of the pigs lying without contact, respectively. This illustrates that older, heavier pigs can tolerate quite a large span of temperatures as long as they do not get too hot, whereas smaller pigs need more heat and have a very narrow interval of optimal temperatures. This effect of weight on the effect of temperature was also found by Spoolder et al. (2012) and by the finding that most fouling happens in the end of the finishing period (e.g. Savary et al., 2009; Jensen et al., 2012; Spoolder et al., 2012), and is probably mainly due to the higher heat production of heavier pigs. When designing the airflow and temperature regulation of pig housing, these optimal temperature ranges should be taken into account. Knowing at which temperature fouling actually occurs could be very helpful when deciding on which actions to use against fouling at different temperatures. The ambient temperature has two inflection points: (1) the temperature at which pigs start to defecate in the lying area with solid floors and (2) the temperature at which pigs start to lie more in the slatted dunging area. Aarnink et al. (2006) found a linear increase in excretions on the solid floor above $19.5^{\circ} \mathrm{C}$ for pigs weighing $65 \mathrm{~kg}$ and housed at $1.02 \mathrm{~m}^{2} / \mathrm{pig}$, whereas the inflection temperature for lying in the dunging area was $25.4^{\circ} \mathrm{C}$. Huynh et al. (2005a) found a linear relationship between temperature and excretions on the solid floor with an average inflection temperature of $20^{\circ} \mathrm{C}$ across relative humidities of $50 \%, 65 \%$ and $80 \%$ at $61 \mathrm{~kg}$ and $1.0 \mathrm{~m}^{2} / \mathrm{pig}$, whereas this was $18.8^{\circ} \mathrm{C}$ for dunging on the slatted floor. Further, both inflection temperatures become lower as the pigs grow. Excreting on the solid floor has been found to start on average at $25^{\circ} \mathrm{C}$ for pigs of $25 \mathrm{~kg}$ and change to $\sim 20^{\circ} \mathrm{C}$ for pigs of $100 \mathrm{~kg}$ (Aarnink et al., 2006), whereas pigs started to lie in the dunging area during the hot summer period at ambient temperatures of $27^{\circ} \mathrm{C}, 23^{\circ} \mathrm{C}$ and $22^{\circ} \mathrm{C}$ for the 25 to 35,50 to 70 and $>85 \mathrm{~kg}$ groups, respectively (Hillmann et al., 2004).

From the results of Huynh et al. (2005a), the pigs seems first to change their lying behaviour and next their dunging behaviour which fits with the theory that pigs change their lying area to be able to thermoregulate and then keep this new lying area clean. However, the results of Aarnink et al. (2006) show the opposite order of behavioural change when only looking at the inflection temperature. When looking more closely, they also found that when more than $28 \%$ of the dunging area was occupied by pigs, it resulted in an increased number of excretions in the lying area. This means that excretion in the lying area had already increased before the maximum occupation of the slatted floors in the dunging area had been reached, but pigs did change their lying behaviour before fouling occurred. One explanation could be that a few pigs start out by changing their lying behaviour to lying in the dunging area, which in the beginning might be sparsely occupied and thus does not motivate the pigs to move further away than the other end of the dunging area to defecate. As more pigs start to change their lying behaviour, the dunging area becomes more occupied and pigs now get up to defecate further away; that is in the lying area. Huynh et al. (2004) also reported that only a maximum of $30 \%$ to $35 \%$ of pigs lay in the dunging area at temperatures above $30^{\circ} \mathrm{C}$ and Hillmann et al. (2004) reported $40 \%$. This may be explained by the finding that pigs do not want to lie too close to each other when it is hot, even when they lie on the cooler 
slats. Besides, if the lying area is wet due to fouling, it would fulfil the pigs' need for cooling as it can be used for wallowing. Further, at these high ambient temperatures, almost all the pigs will be lying (Huynh et al., 2005a). Therefore, it is harder for a pig to move from one end of the pen to the other to defecate, resulting in pigs defecating in the lying area even though there might still be space in the dunging area.

From the above discussion, it is evident that the climate of the pen, and especially the temperature, affects fouling and that it occurs through a change in lying behaviour induced by a need to thermoregulate. The effect of temperature may also overrule the effect of space allowance at high enough temperatures (Hillmann et al., 2005). Thus, to prevent fouling in conventional slaughter pigs with partly slatted floor, it is essential to control the temperature in a pig house or at least to ensure that the designated lying area has the most comfortable climate for lying. Studies conducted so far on fouling in pigs have focused on the risk factors for fouling and ways to lower these risks and thereby prevent fouling. However, use of precision livestock farming may also be a strategy to prevent fouling by developing algorithms that can predict whether a fouling event will happen at pen level. This could, for example, be through surveillance of the lying pattern of the pigs or the ambient temperature of the pen.

\section{Previous experience}

It has been suggested that different forms of training or previous experience could affect fouling of pens. It seems that pigs choose their lying area very soon after being transferred to a new pen. Blackshaw (1981) saw that weaners, being transferred to their slaughter pig pens, decided on their lying area 25 to $60 \mathrm{~min}$ after being mixed and introduced to the pen. Hacker et al. (1994) trained the pigs included in their study. Training consisted of locking the pigs over the dunging area when moving them to the pens, for $2 \mathrm{~h}$, before releasing them into the rest of the clean pen. They found a tendency towards trained pigs fouling more than untrained pigs. The training might have given the pigs an unpleasant experience, thus avoiding the dunging area to some degree afterwards, or the pigs might have chosen the dunging area as their lying area. Rantzer and Svendsen (2001) found that weaners moved from slatted farrowing facilities to a slatted weaner pen had better pen hygiene than weaners staying in the slatted farrowing facilities. This could be explained by a break in the infection chain leading to less diarrhoea. Fouling and diarrhoea have been linked because pigs might not make it to the dunging area in time or they might feel too ill to perform their natural behaviour (Rantzer et al., 1999). Randall et al. (1983) argue that pigs transferred from totally slatted floors are more likely to defecate in the entire area of a partly slatted floor than pigs moved from a completely solid or partially slatted floor. However, they do not present any results or studies to back this up. Not many studies have looked at the connection between fouling and previous experience, thus this field of research still have great potential. For example, it could be interesting to investigate whether fewer pens are fouled if the slaughter pigs experience the same type of flooring through their entire life because they then might find it easier to differentiate between lying and dunging areas of the pen.

\section{Actions to prevent fouling}

Most studies so far on actions to prevent fouling have focused on controlling the climate of the pen either through sprinklers, floor cooling or cooling gradients. Sprinklers can be used to cool pigs when temperatures are high. Huynh et al. (2005b) found that pens with sprinklers had a better production with a higher feed intake and daily gain and a lower skin temperature resulting in fewer pigs lying laterally. Spoolder et al. (2012) found that the amount of space that pigs use is affected by the presence of a showering system activated at temperatures above $25^{\circ} \mathrm{C}$. This meant that pigs lying in the dunging area did not need to change to lateral lying (and thereby taking up more space) because they were cooled by the water. Jensen and Kristensen (2016) saw that when temperatures fell quickly in the dunging area, as a result of sprinklers being turned on, the risk of undesired events such as fouling was reduced. Thus, use of sprinklers when temperatures are high helps to reduce fouling through cooling of the pigs, but it will also make the dunging area wet and undesirable for the pigs to lie in. Instead of making the dunging area undesirable, it would be better to increase the desirability of the lying area, for example, through floor cooling in the solid floors. Geers et al. (1990) used water tubes in the floors to control the temperature, thereby achieving a microclimate that encouraged weaned pigs from 10 to $30 \mathrm{~kg}$ to lie in the designated lying area. Similar results were found by Huynh et al. (2004) who found less fouling and fewer pigs lying in the dunging area in pens with cooled floors. Randall et al. (1983) did an experiment with cooling gradients in pens for slaughter pigs. They found that pens were cleaner with an air inflow that ensured that the lying area was warmer and with lower air speed than the dunging area. However, this would probably have the opposite effect if the temperature in the room is not kept optimally low. The best temperature gradient tested in the experiment was with the lying end being $2.6^{\circ} \mathrm{C}$ higher than the lower critical temperature and the dunging end being $3.7^{\circ} \mathrm{C}$ lower than the lower critical temperature, with a total cooling gradient of $6.3^{\circ} \mathrm{C}$. The lower critical temperature was not defined in the study but, as mentioned earlier, Hillmann et al. (2004) defined these as ranging from $19^{\circ} \mathrm{C}$ for pigs of 25 to $35 \mathrm{~kg}$ to $5^{\circ} \mathrm{C}$ for pigs of $>85 \mathrm{~kg}$. Pens in which the airflow was directed first to the lying area and then towards the dunging area were significantly dirtier. This could be explained by pigs avoiding lying in the draughty cooler lying area and thus initiating fouling. Another aspect of controlling the climate is to decrease draught in the lying area. Hacker et al. (1994) found pens with open partitions in the entire pen to be dirtier than closed pens even though both pen types had open partitions in the dunging area. The closed pen partitions may result in reduced draught and maintain a temperature gradient with a warmer lying area compared with the 
dunging area. However, another theory is that the open partitions in the entire pen could provoke a need to mark not just the dunging area but the whole length of the pen with dung as a territorial behaviour (Hacker et al., 1994). An alternative to control the climate of the pen and especially the designated lying area to prevent fouling may be to increase the comfort of the surface in the lying area. Savary et al. (2009) investigated the effect of a synthetic plate in the lying area, compared with concrete or a slight straw layer, on fouling. Lying area was $75 \%$ of the pen and the synthetic plate covered this area entirely. They found that the proportion of pigs lying in the dunging area was higher in pens with a synthetic plate or straw compared with pens with concrete flooring. Again, fouling increased as temperature increased ranging from $4^{\circ} \mathrm{C}$ to $28^{\circ} \mathrm{C}$ and this increase was steeper in pens with a synthetic plate or straw. They concluded that the synthetic plate and straw may cause heat loss problems and more fouling because the pigs instead choose to lie in the dunging area. Thus, increasing the comfort of the surface in the lying area did not reduce fouling but had the opposite effect. However, Vermeer et al. (2015) found that adding a rooting area to outdoor runs of organic pigs improved the cleanliness of the outdoor area. Thus, materials such as hay or straw may help pigs differentiate areas of the pen as long as it does not limit their thermoregulatory behaviour. Aarnink et al. (1997b) instead reduced the comfort of the dunging area through $5 \mathrm{~cm}$ high studs on the slatted area which did result in cleaner pens. This solution does not, however, reduce heat stress at high temperatures and might increase the risk of lameness and thus, does not improve the welfare of the pigs. An alternative action against fouling found in the literature investigated here was to design the pen with a step down between the designated lying and dunging area. The half of the lying area closest to the step down, was found to have significantly less excreta when the step down was installed than when it was not (Randall et al., 1983). All in all, controlling the climate through sprinklers, floor cooling, cooling gradients or closed pen partitions seems effective in reducing fouling, whereas the same applies for installing a step down between the designated lying and dunging area and decreasing the comfort of the dunging area surface. Increasing the comfort of the lying area surface will probably also help prevent fouling, but it is important always to have in mind whether the surface will also change pigs' ability to thermoregulate.

\section{Conclusion and future perspectives}

From the studies included in this review on factors affecting fouling, it is evident that multiple factors affect fouling, but ensuring the right climate while considering the weight of the pigs seems the most effective way to control fouling. Other aspects important to consider is that the space allowance is neither too low nor too high and that the slatted floor should be comfortable for the pigs to walk on. However, if the climate is not appropriate, most other factors will not matter. If the ambient temperature cannot be kept in the optimal range, sprinklers or floor cooling are effective in cooling the pigs. Suggestions for future studies have been made throughout the review, but most importantly, they should focus on optimising the lying area instead of making the dunging area less desirable. Further, a new approach may be to predict fouling events at pen level through changes in lying pattern and temperature, thereby preventing it from happening.

\section{Acknowledgments}

The study was granted by the Green Development and Demonstration Programme under the Ministry of Food, Agriculture and Fisheries, Denmark (project StrawWell j.nr.: 34009-13-0736) and by the Danish Council for Strategic Research (The PiglT project, Grant no. 11-116191).

\section{References}

Aarnink AJA, Koetsier AC and Vandenberg AJ 1993. Dunging and lying behaviour of fattening pigs in relation to pen design and ammonia emission. Livestock Environment IV, 1176-1184.

Aarnink AJA, Schrama JW, Heetkamp MJW, Stefanowska J and Huynh TTT 2006. Temperature and body weight affect fouling of pig pens. Journal of Animal Science 84, 2224-2231.

Aarnink AJA, Swierstra D, vandenBerg AJ and Speelman L 1997b. Effect of type of slatted floor and degree of fouling of solid floor on ammonia emission rates from fattening piggeries. Journal of Agricultural Engineering Research 66, 93-102.

Aarnink AJA, Wagemans MJM and vandenBerg AJ 1997a. Housing for growing pigs meeting the needs for animal, stockman and environment. Livestock Environment V, 86-92.

Aarnink AJA, vandenBerg AJ, Keen A, Hoeksma P and Verstegen MWA 1996. Effect of slatted floor area on ammonia emission and on the excretory and lying behaviour of growing pigs. Journal of Agricultural Engineering Research 64, 299-310.

Blackshaw JK 1981. Environmental-effects on lying behavior and use of trough space in weaned pigs. Applied Animal Ethology 7, 281-286.

Ekkel ED, Spoolder HAM, Hulsegge I and Hopster H 2003. Lying characteristics as determinants for space requirements in pigs. Applied Animal Behaviour Science 80, 19-30.

Geers R, Goedseels V, Parduyns G, Nijns P and Wouters P 1990. Influence of floor type and surface-temperature on the thermoregulatory behavior of growing pigs. Journal of Agricultural Engineering Research 45, 149-156.

Hacker RR, Ogilvie JR, Morrison WD and Kains F 1994. Factors affecting excretory behavior of pigs. Journal of Animal Science 72, 1455-1460.

Hillmann E, Mayer C, Gygax L and Schrader L 2005. Effects of space allowance on behavioural and adrenocortical reactions to elevated temperatures in fattening pigs. Landbauforschung Volkenrode 55, 255-260.

Hillmann E, Mayer C and Schrader L 2004. Lying behaviour and adrenocortical response as indicators of the thermal tolerance of pigs of different weights. Animal Welfare 13, 329-335.

Huynh TTT, Aarnink AA, Gerrits WJJ, Heetkamp MJH, Canh TT, Spoolder HAM, Kemp B and Verstegen MWA 2005a. Thermal behaviour of growing pigs in response to high temperature and humidity. Applied Animal Behaviour Science $91,1-16$.

Huynh TTT, Aarnink AJA, Spoolder HAM, Verstegen MWA and Kemp B 2004. Effects of floor cooling during high ambient temperatures on the lying behavior and productivity of growing finishing pigs. Transactions of the ASAE 47, 1773-1782.

Huynh TTT, Aarnink AJA and Verstegen MWA 2005b. Reactions of pigs to a hot environment. Livestock Environment VII, 18-20, 544pp. American Society of Agricultural and Biological Engineers, Beijing, China.

Jensen DB and Kristensen AR 2016. Temperature as a predictor of fouling and diarrhea in slaughter pigs. Livestock Science 183, 1-3. 


\section{Larsen, Bertelsen and Pedersen}

Jensen T 2003. Flokstørrelse og gulvudformning i slagtesvinestier med delvist spaltegulv (Group size and floor design of finisher pens with partially slatted floors). Landsudvalget for Svin, Den rullende Afprøvning (National Committee for Pigs, Rolling Tests), Copenhagen, Denmark. Retrieved on 1 May 2017 from http://svineproduktion.dk/publikationer/kilder/lu_medd/medd/603. Jensen T, Nielsen CK, Vinther J and D'Eath RB 2012. The effect of space allowance for finishing pigs on productivity and pen hygiene. Livestock Science 149, 33-40. Olczak K, Nowicki J and Klocek C 2015. Pig behaviour in relation to weather conditions - a review. Annals of Animal Science 15, 601-610.

Olsen A, Dybkjær L and Simonsen H 2001. Behaviour of growing pigs kept in pens with outdoor runs: II. Temperature regulatory behaviour, comfort behaviour and dunging preferences. Livestock Production Science 69, 265-278.

Randall JM, Armsby AW and Sharp JR 1983. Cooling gradients across pens in a finishing piggery: II. Effects on excretory behavior. Journal of Agricultural Engineering Research 28, 247-259.

Rantzer D and Svendsen J 2001. Slatted versus solid floors in the dung area: comparison of pig production system (moved versus not moved) and effects on hygiene and pig performance, weaning to four weeks after weaning. Acta Agriculturae Scandinavica Section A - Animal Science 51, 175-183.

Rantzer D, Westroem B and Svendsen J 1999. Effects of pen hygiene and moving the pigs at weaning on pig production and health during the first 8 weeks.
Rapport-Sveriges Lantbruksuniversitet, Institutionen foer Jordbrukets Biosystem och Teknologi (JBT), SLU, Alnarp.

Salomon E, Akerhielm H, Lindahl C and Lindgren K 2007. Outdoor pig fattening at two Swedish organic farms - spatial and temporal load of nutrients and potential environmental impact. Agriculture Ecosystems \& Environment 121, 407-418.

Savary P, Gygax L, Wechsler B and Hauser R 2009. Effect of a synthetic plate in the lying area on lying behaviour, degree of fouling and skin lesions at the leg joints of finishing pigs. Applied Animal Behaviour Science 118, 20-27.

Smulders D, Verbeke G, Mormede P and Geers R 2006. Validation of a behavioral observation tool to assess pig welfare. Physiology \& Behavior 89, 438-447.

Spoolder HAM, Aarnink AAJ, Vermeer HM, van Riel J and Edwards SA 2012. Effect of increasing temperature on space requirements of group housed finishing pigs. Applied Animal Behaviour Science 138, 229-239.

Stolba A and Wood-Gush D 1989. The behaviour of pigs in a semi-natural environment. Animal production 48, 419-425.

Sumena K, Lucy K, Chungath J, Ashok N and Harshan K 2010. Regional histology of the subcutaneous tissue and the sweat glands of large white Yorkshire pigs. Tamilnadu Journal of Veterinary \& Animal Sciences 6, 128-135.

Vermeer HM, Altena H, Vereijken P and Bracke M 2015. Rooting area and drinker affect dunging behaviour of organic pigs. Applied Animal Behaviour Science 165, 66-71. 